\title{
HOSPITAL MEDICINE
}

\section{Getting By: Underuse of Interpreters by Resident Physicians}

\author{
Lisa C. Diamond, MD, MPH $H^{1,2,5}$, Yael Schenker, MD', Leslie Curry, PhD, MPH ${ }^{1,4}$, \\ Elizabeth H. Bradley, $P h D^{1,4}$, and Alicia Fernandez, $M D^{3}$
}

${ }^{1}$ Robert Wood Johnson Clinical Scholars Program, Yale University School of Medicine, New Haven, CT, USA; ${ }^{2}$ VA Medical Center, West Haven, CT, USA; ${ }^{3}$ Division of General Internal Medicine, University of California at San Francisco, San Francisco, CA, USA; ${ }^{4}$ Division of Health Policy and Administration, Yale University School of Public Health, New Haven, CA, USA; ${ }^{5}$ Palo Alto Medical Foundation Research Institute, Palo Alto, CA, USA.

BACKGROUND: Language barriers complicate physicianpatient communication and adversely affect healthcare quality. Research suggests that physicians underuse interpreters despite evidence of benefits and even when services are readily available. The reasons underlying the underuse of interpreters are poorly understood.

OBJECTIVE: To understand the decision-making process of resident physicians when communicating with patients with limited English proficiency (LEP).

DESIGN: Qualitative study using in-depth interviews.

PARTICIPANTS: Internal medicine resident physicians $(n=20)$ from two urban teaching hospitals with excellent interpreter services.

APPROACH: An interview guide was used to explore decision making about interpreter use.

RESULTS: Four recurrent themes emerged: 1) Resident physicians recognized that they underused professional interpreters, and described this phenomenon as "getting by;" 2) Resident physicians made decisions about interpreter use by weighing the perceived value of communication in clinical decision making against their own time constraints; 3) The decision to call an interpreter could be preempted by the convenience of using family members or the resident physician's use of his/her own second language skills; 4) Resident physicians normalized the underuse of professional interpreters, despite recognition that patients with LEP are not receiving equal care.

CONCLUSIONS: Although previous research has identified time constraints and lack of availability of interpreters as reasons for their underuse, our data suggest that the reasons are far more complex. Residents at the study institutions with interpreters readily available found it easier to "get by" without an interpreter, despite misgivings about negative implications for quality of care. Findings suggest that increasing interpreter use will require interventions targeted at both individual physicians and the practice environment.

Received July 11, 2008

Revised October 14, 2008

Accepted November 17, 2008

Published online December 17, 2008
KEY WORDS: communication; doctor-patient relationships; physician behavior; decision making; qualitative research.

$\mathrm{J}$ Gen Intern Med 24(2):256-62

DOI: $10.1007 / \mathrm{s} 11606-008-0875-7$

(c) Society of General Internal Medicine 2008

\section{INTRODUCTION}

Effective communication between physicians and patients is essential to the provision of high quality, patient-centered health care $^{1}$. Language barriers encountered in the care of patients with limited English proficiency (LEP), a growing segment of the U.S. population ${ }^{2}$, adversely affect healthcare quality. Patients with LEP may have decreased access to acute care and preventive services ${ }^{3-6}$, decreased satisfaction with care $^{7,8}$, poor understanding of instructions or medications ${ }^{9,10}$, longer hospital stays ${ }^{11}$, and an increased risk of medical errors and misdiagnoses ${ }^{12-16}$.

The use of professional interpreters improves the quality of care for patients with LEP, resulting in higher patient satisfaction $^{17}$, fewer errors in communication ${ }^{14}$, reduced disparities in utilization of services ${ }^{18}$, and improved clinical outcomes ${ }^{19}$. Despite accumulating evidence of the benefits of professional interpreter use, recent studies suggest that that they are underused by physicians ${ }^{20-23}$. Two studies conducted at hospitals with professional interpreters available 24 hours per day found that resident physicians frequently relied upon their own limited language skills, patients' family members, or other untrained interpreters to communicate with patients with $\operatorname{LEP}^{20,21}$. In another study, almost one quarter of patients with LEP felt that an interpreter should have been used, especially when the clinician used his or her own limited Spanish to communicate ${ }^{22}$.

The specific reasons underlying professional interpreter underuse are not well understood. While physicians cite time pressures and limited interpreter availability, professional interpreters are underused even when readily available $e^{24,25}$, suggesting that other factors may play an important role. We conducted a qualitative study to understand resident physicians' experiences when caring for patients with LEP. To our knowledge, this is the first in-depth examination of decision making about interpreter use, a necessary step toward improving the quality of care for patients with LEP. 


\section{METHODS}

We conducted a qualitative study using in-depth interviews with internal medicine resident physicians from all three years of residency at two urban teaching hospitals, one on the East Coast and one on the West Coast. We selected residents from a single specialty in order to create a homogenous sample with regard to the types of decisions typically made while caring for patients with LEP. We focused on physicians-in-training because they are often the front-line clinicians in urban hospitals that care for large numbers of patients with LEP and hence likely to be "information rich," that is, have direct experience with the phenomenon of interest ${ }^{26}$. Interpreter services at the East Coast hospital included on site, in-person staff interpreters for Spanish (88\% of requests are for Spanish interpreters) available 12-17 hours per day, 7 days per week. For the 85 requested languages other than Spanish, in-person interpreters are available by appointment. In addition, overthe-phone interpreter services for 140 different languages are available through a commercially available subscription service 24 hours per day, 7 days per week ${ }^{27}$. The interpreter services department at the West Coast hospital provides on-site professional staff interpreters for 22 languages, 16 hours per day, 7 days per week. Nine additional languages are available by prearrangement through an "on-call" system of interpreters ${ }^{28}$. The West Coast hospital also subscribes to a telephone interpreter service that can be accessed through any bedside phone, at any time, and provides interpreting in 170 languages. In prior research, physicians at the West Coast hospital perceived the interpreter services as readily available and of high quality ${ }^{29}$. Neither hospital collected data on wait times for professional interpreter arrival. In both hospitals, the managers of interpreter services reported that waiting times for a professional interpreter varied by the specific language needed and the hospital location. For more common languages and standard locations, the wait averaged about 5-15 minutes for an in-person interpreter and less than a minute to connect to a telephone interpreter ${ }^{27,28}$. The research protocol was approved by the Human Investigation Committee of each institution. Verbal consent was obtained from all study participants.

The internal medicine program director at each site provided a list of residents in post-graduate years 1-3 who had completed a rotation at the participating hospital within the past 6 months. A random subset of participants at each site was chosen from this list in order to maximize credibility and reduce selection bias ${ }^{26}$. Interviews were scheduled in order of the randomization list. Only one eligible resident chose not to participate in the study, due to reported time constraints.

The discussion guide included open-ended questions (Appendix) about residents' experiences with interpreter use, barriers to using interpreters for individual physicians, and perceptions of the impact of use and underuse of interpreters on patient care. Twenty interviews were conducted, at which time the research team determined that theoretical saturation had been reached ${ }^{30-32}$. We employed the following principles to achieve saturation: development of a cohesive theoretical sample, deliberate consideration of negative cases, definition of relatively narrow focus of inquiry and regular team assessment of the adequacy and comprehensiveness of results ${ }^{30}$. All interviews at the East Coast hospital were conducted by one investigator (LCD) and interviews at the West Coast hospital were conducted by another (YS). Interviews were audiotaped and transcribed by a professional transcription service and their quality was verified by the respective interviewer at each site. A brief survey, adapted from a published study of cultural competence in residents, was administered after the interview to capture information about participants' demographics and language skills ${ }^{24}$.

We performed data analysis using the constant comparative method $^{26,31}$. Codes were developed iteratively and refined to identify conceptual segments of the data ${ }^{33}$. The team reviewed the code structure throughout the analytic process and revised the scope and content of codes as needed. The code structure began with five codes and was developed into the final code structure with 14 codes, which were integrated into the four recurrent themes. Data analyses were performed by the entire research team. One member of the research team (LCD) coded all of the transcripts using Atlas.ti version 5.0. The other team members (YS, LC, EHB, and $\mathrm{AF}$ ) double and triple coded portions of the data. Disagreements in coding were discussed until a consensus was reached. Additional strategies to enhance credibility of our findings included creation of an audit trail documenting the data analysis process ${ }^{34}$ and participant confirmation of the findings ${ }^{35}$.

\section{RESULTS}

Study participants (Table 1) ranged in age from 26 years to 33 years; $85 \%$ were born in the United States. Eighty percent reported having the ability to speak a foreign language well enough to provide care. Spanish was the foreign language most commonly spoken by participants. Almost all partici-

Table 1. Description of Sample

\begin{tabular}{lc}
\hline \hline Characteristic & Result $^{*}(\mathrm{~N}=\mathbf{2 0})$ \\
\hline Age & $263(28.9)$ \\
Female & $13(65)$ \\
Race/Ethnicity & \\
White & $12(60)$ \\
Black & $0(0)$ \\
Asian or Pacific Islander & $4(20)$ \\
Native American or Alaska Native & $1(5)$ \\
Hispanic/Latino/Latina & $3(15)$ \\
U.S. born & $17(85)$ \\
Other language (“Speak well enough to provide care”) & $16(80)$ \\
Specific other languages $\dagger$ & \\
Spanish & $14(70)$ \\
French & $3(15)$ \\
Italian & $2(10)$ \\
Mandarin & $1(5)$ \\
German & $1(5)$ \\
Greek & $1(5)$ \\
Kannada & $1(5)$ \\
U.S. medical school graduate & $20(100)$ \\
International medical work & $8(40)$ \\
Percent of patients with LEP & $60(50)$ \\
Frequency of language barriers & \\
Never & $0(0)$ \\
Rarely & $1(5)$ \\
Sometimes & $9(45)$ \\
Often & $10(50)$ \\
\hline
\end{tabular}

* Results are range (mean) for age and number (\%) for all other variables $\dagger$ Total percentages are $>100$ because subjects could specify up to four additional languages spoken 
pants reported that they interacted with patients with LEP "sometimes" or "often."

Four recurrent themes emerged that characterized physician decision making about interpreter use: 1) Resident physicians recognized that they underused professional interpreters, and described this phenomenon as "getting by;" 2) Resident physicians made decisions about interpreter use by weighing the perceived value of communication in clinical decision making against their own time constraints; 3) The decision to call an interpreter could be preempted by the convenience of using family members or the resident physician's use of his/her own second language skills; 4) Resident physicians normalized the underuse of professional interpreters, despite recognition that patients with LEP are not receiving equal care.

\section{Resident Physicians Recognized that they Underused Professional Interpreters, and Described this Phenomenon as "Getting By"}

Resident physicians described both their own and their colleagues' underuse of professional interpreters. This practice, described by some resident physicians as "getting by," included communicating through gestures, using limited second language skills, and relying on histories obtained by other physicians. All of the resident physicians recalled instances of their own non-use of interpreters. One resident physician explained his practice and that of his colleagues as follows:

"I know that when people are very pushed for time, they may or may not call an interpreter. They may just 'get by' on the few words they know in different languages for like 'pain' and 'take a deep breath' and just fumble through. You probably get a pretty bad history and maybe not a great physical exam either."

Another resident physician described the ability to forego interpreters by using gestures to communicate with patients:

"[A] lot of times you can position them the way you want them to and then just listen to their lungs or their hearts without them having to really do much of anything... [Y]ou can mimic things; if you are asking them if they have vomited overnight, you can imitate throwing up and they will be like, 'Oh no, no, no' or 'yes, I did.' It's difficult to get details surrounding that but you can get a general idea."

Senior level residents described performing physical exams without an interpreter present while relying on junior team members to elicit a history from patients, a deviation from usual practice at these hospitals:

"When it is very busy at night, there have been many patients that I have seen who are fluent only in one language, and I will go in and I will do my kind of quick, succinct R3 exam and leave and essentially introduce myself with head nods and hellos and ask by...body language, if it is okay if I can examine them by showing my stethoscope or something... and I will examine them, but I would not have actually spoken to them in their language or gotten a history from them."

\section{Resident Physicians Made Decisions about Interpreter use by Weighing the Perceived Value of Communication in Clinical Decision Making Against their Own Time Constraints}

Resident physicians considered the importance of communication in the clinical scenario when deciding whether or not to use a professional interpreter. They mentioned weighing the perceived benefit from using an interpreter against their own workload. One participant described this tension in this way:

"The time constraints and hassle factor... we're always doing the calculation of like: How high yield is this going to be? Is it really worth the time invested? Will I gain anything?... Are we going to be able to really advance care here by getting a translator?"

Many resident physicians had their own guidelines for calling a professional interpreter. These residents linked interpreter use to high-stakes clinical interactions, such as family meetings to determine goals of care, in which the importance of communication outweighed the inconvenience of obtaining a professional interpreter. One resident physician described her criteria for calling an interpreter as follows:

"I think when it comes to really important conversations... treatment decisions, end of life care, comfort care, not comfort care, coumadin, no coumadin. Those are times when... if you put ethics on a scale, like really more unethical not to [get an interpreter] and/or really more dangerous not to."

Other resident physicians did not have established standards for determining when an interpreter was necessary, instead considering the importance of communication on a case-by-case basis. One resident physician described making the decision about whether an interpreter was needed for a given clinical scenario as follows:

"It's really variable depending on the exact situation... what sort of information I am trying to get out of [patients], and what time of day it is and what my location is... Also if it's not the first time I am seeing them, if I am just pre-rounding on the patient or just checking in on them after seeing them once or several times before, then I think I often can hobble by without one."

\section{The Decision to Call an Interpreter Could be Preempted by the Convenience of using Family Members or the Resident Physician's Use of his/her Own Second Language Skills}

In contrast to the carefully-considered decisions described above, resident physicians reported less deliberation around the option of using family members or their own limited language skills. Residents found that using patients' family members as ad hoc interpreters was time saving and required little effort. Bilingual family members present at the patient's bedside could provide immediate responses to residents' questions. Resident physicians reported that they rarely 
decided to wait for a professional interpreter when a family member was available.

"A lot of times, it wasn't an intentional 'I am going to use this [family member] as a translator,' but more 'This person speaks Spanish and wow, this person that is with them is bilingual, we'll use them as a translator,' it was never a conscious decision, 'I am going to use them over this person,' but 'wow, this is convenient, let me do this,' until, like I said, I realized it was a bad idea."

Resident physicians discussed the potential for inaccurate or incomplete information exchanges and breaches of patient confidentiality when using family members as interpreters. In these discussions, residents reported having had some training on how to access and work with professional interpreters during residency orientation or in medical school, but said they had received little guidance on when professional interpreters should be used. Residents also found that their patients' bilingual family members experienced conflict between their role as an interpreter and their primary role as the relative of an ill patient, as described by a resident:

"He actually ended up having a large brain mass that was probably [malignant]... I think that the fault initially was really ours for coasting along for probably two days thinking we're getting from the sons what we need to get... [Y]ou see children or relatives doing their best to try to be the mediator and the translator. And then as soon as they don't have to play that role anymore they suddenly have so much more to say because they're not trying to figure out how to say it in English."

Resident physicians reported that the convenience of using one's own second language skills, even when limited in fluency, sometimes preempted the decision to call for professional interpreters. These instances may particularly impact Spanish speaking patients, since this was the most common additional language spoken by participants. Resident physicians also said that they enjoyed practicing their own second language skills and felt that direct communication was beneficial to their relationship with patients, despite language limitations. Some residents prioritized the opportunity to improve these skills, while recognizing them as inadequate.

"[W]hen I have Spanish speaking patients, I really relish the opportunity to try to practice my Spanish, but I also do not think that I give the best care because... I don't think I'm fluent enough to be very eloquent with them so that there... can be some misunderstandings."

\section{Resident Physicians Normalized the Underuse of Professional Interpreters, Despite Recognition that Patients with LEP are not Receiving Equal Care}

Many resident physicians felt that underuse of professional interpreters had become the norm. One participant described the use of interpreters by physicians in general as follows:

"I think on a daily basis... people are really trying to get around [calling an interpreter] if they can."
Another participant described the practice of using a professional interpreter only for the admission interview and major events, while recognizing that patients who speak English are treated differently:

"I think it is pretty standard to get a translator when something big has to be communicated. I think a lot of medicine and good medical care has to do with smaller things than the major events. So, that is why I think patients who do not speak English are getting inferior care, unfortunately."

Some resident physicians expressed ambivalence about their own non-use of interpreters for their patients with LEP. While admitting that their own practice was similar to their peers' practices, they still raised questions about differences in the quality of care provided to patients with LEP.

"I guess I feel like someone is talking to [the patient] and getting a good history at some point... It's okay if I kind of come in and do a little bit more of a perfunctory exam and history, knowing that I will at some point talk to them with an interpreter when time is available. But in some ways..., it does not seem all that fair because English-speaking patients-I talk to them in their own language easily even on-call, even when I am busy."

In contrast, some resident physicians expressed uneasiness, guilt and frustration with the differences in communication they observed for their patients with LEP. One participant shared her dissatisfaction with what she perceived as a common practice of underusing interpreters:

"I feel guilty... because I feel like I'm not doing my job, and it also makes me feel very frustrated and upset at how our hospitals and clinics are run - that we allow this to happen... There is a lot of sentiment that 'well maybe [patients with LEP] shouldn't be getting healthcare.' I think the reason that I feel badly is because I know that I am not giving equal care to my patients."

When describing the messages they received about interpreter use from supervising physicians, residents emphasized that communication was frequently a low priority. One participant explained how she thought the system could change if supervising physicians emphasized the importance of professional interpreter use for patients with LEP:

"I think that a lot of us try to get by without using interpreters... Overall, we do not use interpreters as much as we should... I think that [attendings or residents] maybe even just emphasizing that we should use interpreters on a daily basis might be [helpful]... maybe making it a standard."

\section{DISCUSSION}

In this qualitative study, resident physicians described not using professional interpreters for their patients with LEP, a routine practice termed "getting by." Although residents in our 
study knew how to access interpreter services and recognized that interpreters contribute to better care, they made decisions about interpreter use after weighing the benefits of accurate communication against competing demands on their time. For routine patient care, residents in our study reported that they got by using gestures, limited second language skills and/or family members, while often reserving the use of professional interpreters for interactions they perceived as being complex or having high stakes. Many residents in our study felt dissatisfied with the care they provided to patients with LEP and frustrated by the inequities in care they perceived.

Our interviews suggest that there are complex and interrelated factors underlying resident physician decisions about interpreter use. First, resident physicians in our study seemed to view communication mainly as a means of gathering necessary clinical data, and less as an opportunity to address the concerns of their hospitalized patients. In this view of communication, primarily weighing the clinical stakes when making the decision to call an interpreter is reasonable. Physician-centered communication, while not unusual ${ }^{36}$, may be more common in the setting of language barriers ${ }^{37}$. Such limited communication also has important implications for rapport building and the connection between physicians and patients that lies at the heart of the therapeutic relationship $^{38}$. Second, residents in our study were often unaware of the difficulties associated with using untrained interpreters, particularly family members, and reported discovering the disadvantages of this approach over time. Coupled with a physician-centered view of communication, this lack of awareness rendered the convenience of using family members an even more attractive option. Third, residents in our study made decisions about professional interpreter use in an environment in which underuse of interpreters was common, standards for communicating with patients with LEP were unclear, and other aspects of care were more valued. Under such circumstances, these residents found it difficult to change their individual practice, despite misgivings about the quality of care provided.

Our study suggests that increasing professional interpreter use will require interventions at both the level of the individual physician and the practice environment. At the physician level, education about the challenges of caring for patients with LEP, including the potential for adverse outcomes associated with the use of untrained interpreters, and the advantages of using professional interpreters to achieve accurate communication and improved understanding of cultural differences may help resident physicians make appropriate decisions about interpreter use ${ }^{25,39}$. Professional standards regarding appropriate use of second language skills by resident physicians should be established to help guide those who choose to use these skills. Finally, resident physicians need role models to reinforce appropriate use of professional interpreters. Recognition from supervising physicians that appropriate use of language services will improve the safety and quality of care for patients with LEP has the potential to translate into behavior change for physicians-in-training.

At the level of the practice environment, increasing professional interpreter use requires establishing clear norms and structural changes, as has been observed in several quality improvement efforts ${ }^{40,41}$. Hospitalized patients with LEP should have a conversation in their preferred language with their treating physician at least daily. Meeting this standard will require substantial changes in the hospital practice environment. Such changes are most likely to be successful if they are endorsed by senior hospital leadership and are viewed as patient safety and quality improvement efforts ${ }^{40,42}$. The use of routine and novel technology, such as computer-order entry for interpreter services, wireless speaker phones, interpreter kiosks, and video interpreting, may also help to increase professional interpreter use.

Although this study has important implications for the care of patients with LEP, there are limitations to consider. We focused our recruitment on internal medicine resident physicians at two large, urban teaching hospitals. Accordingly, the experiences of our participants may not reflect the experiences of physicians who have completed their post-graduate training, resident physicians in other medical specialties, or physicians in other geographic areas. At the same time the two hospitals in which the study took place have diverse patient populations, robust interpreter services, and well-regarded residency training programs, suggesting that our findings may apply to other institutions. Additionally, all of the study participants were graduates of US medical schools and most were born in the US, which, while reflective of the demographics of the residency programs studied, is not representative of most national internal medicine residency programs. The use of interpreters by resident physicians born or trained outside of the US may differ and is an important topic for future study. The participants' language abilities were assessed using one screening question, which has been used in previous studies but has not been validated $^{24}$. Further research is needed to develop standards for assessing language proficiency in physicians and to determine the proficiency level at which providing language-concordant care is appropriate. Finally, our study was qualitative in nature, and therefore not designed to quantify the frequency of nonuse of professional interpreters. Our findings do offer insight into why professional interpreters are underused and thus can be helpful in designing interventions to improve the use of professional interpreters.

In our study, resident physicians described complex reasons for their underuse of professional interpreters. These findings suggest that increased interpreter service availability and education for residents about how to access interpreter services are unlikely to be sufficient to change patterns of interpreter use. Quality improvement efforts that focus on integrating language services into the hospital environment while changing organizational and professional norms about communication with patients with LEP are needed.

\footnotetext{
Acknowledgments: Dr. Diamond was supported during this research by the Robert Wood Johnson Clinical Scholars Program and the United States Department of Veterans Affairs. Dr. Schenker is a General Internal Medicine Fellow at UCSF, funded by the Department of Health and Human Services, Health Resources and Services Administration (DHHS HRSA D55HP05165). Dr. Bradley is supported by the Patrick and Catherine Weldon Donaghue Medical Research Foundation Investigator Award. Dr. Fernandez is supported by an NIH Career Development Award (K23-RRO18324-01).

The data presented in this manuscript were presented at both the California Regional Society of General Internal Medicine Meeting in San Francisco, CA in March of 2008 and the Society of General Internal Medicine Annual Meeting in Pittsburgh, PA in April of 2008.
}

Conflict of Interest: None disclosed. 
Corresponding Author: Lisa C. Diamond, MD, MPH; Palo Alto Medical Foundation Research Institute, Ames Building, 795 El Camino Real, Palo Alto, CA 94301, USA (e-mail: diamondl@pamfri.org).

\section{REFERENCES}

1. Institute of Medicine. Crossing the Quality Chasm: A New Health System for the Twenty-first Century. Washington: National Academy Press: 2001.

2. Shin HB, Bruno R. United States Census Report: Language Use and English-Speaking Ability: 2000. Available at: http://www.census.gov/ prod/2003pubs/c2kbr-29.pdf. Accessed November 17, 2008.

3. Woloshin S, Schwartz LM, Katz SJ, Welch HG. Is language a barrier to the use of preventive services. J Gen Intern Med. 1997;12(8)472-7.

4. Diehl AK, Westwick TJ, Badgett RG, Sugarek NJ, Todd KH. Clinical and sociocultural determinants of gallstone treatment. Am J Med Sci. 1993;305(6)383-6.

5. Todd KH, Samaroo N, Hoffman JR. Ethnicity as a risk factor for inadequate emergency department analgesia. JAMA. 1993;269 (12): 1537-9.

6. Cheng EM, Chen A, Cunningham w. Primary language and receipt of recommended health care among Hispanics in the United States. J Gen Intern Med. 2007;22(S2):283-8.

7. Carrasquillo O, Orav EJ, Brennan TA, Burstin HR. Impact of language barriers on patient satisfaction in an emergency department. J Gen Intern Med. 1999;14(2):82-7.

8. Morales LS, Cunningham WE, Brown JA, Liu H, Hays RD. Are Latinos less satisfied with communication by health care providers. J Gen Intern Med. 1999;14(7):409-17.

9. Wilson E, Chen AHM, Grumbach K, Wang F, Fernandez A. Effects of limited English proficiency and physician language on health care comprehension. J Gen Intern Med. 2005;20(9):800-6.

10. Atchison KA, Black EE, Leathers R, et al. A qualitative report of patient problems and postoperative instructions. J Oral Maxillofac Surg. 2005;63(4):449-56.

11. John-Baptiste A, Naglie G, Tomlinson G, et al. The effect of English language proficiency on length of stay and in-hospital mortality. J Gen Intern Med. 2004;19(3):221-8

12. Divi C, Koss RG, Schmaltz SP, Loeb JM. Language proficiency and adverse events in US hospitals: A pilot study. Int $\mathrm{J}$ Qual Health Care. 2007; 19(2):60-7.

13. Marcos LR. Effects of interpreters on the evaluation of psychopathology in non- English-speaking patients. Am J Psychiatr. 1979;136(2):171-4.

14. Flores G, Laws MB, Mayo SJ, et al. Errors in medical interpretation and their potential clinical consequences in pediatric encounters. Pediatrics. 2003;11(1):16-14

15. Flores G. Language barriers to health care in the United States. N Engl Med. 2006;355(3):229-31.

16. Bard MR, Goettler CE, Schenarts PJ, et al. Language barrier leads to the unnecessary intubation of trauma patients. Am Surgeon. 2004;70 (9):783-6.

17. Baker DW, Hayes R, Fortier JP. Interpreter use and satisfaction with interpersonal aspects of care for Spanish-speaking patients. Med Care. 1998;36(10): 1461-70.

18. Jacobs EA, Lauderdale DS, Meltzer D, Shorey JM, Levinson W, Thisted RA. Impact of interpreter services on delivery of health care to limited-English-proficient patients. J Gen Intern Med. 2001;16(7):46874.

19. Karliner LS, Jacobs EA, Chen AH, Mutha S. Do professional interpreters improve clinical care for patients with limited English proficiency? A systematic review of the literature. Health Serv Res. 2007;42 (2):727-54

20. Burbano O'Leary SC, Federico S, Hampers LC. The truth about language barriers: one residency program's experience. Pediatrics. 2003; $111(5$ Pt 1):e569-73.

21. Yawman D, McIntosh S, Fernandez D, Auinger P, Allan M, Weitzman M. The use of Spanish by medical students and residents at one university hospital. Acad Med. 2006;81(5):468-73.

22. Baker DW, Parker RM, Williams MV, Coates WC, Pitkin K. Use and effectiveness of interpreters in an emergency department. JAMA. 1996;275(10):783-8.
23. Schenker Y, Wang F, Selig SJ, Ng R, Fernandez A. The Impact of Language Barriers on Documentation of Informed Consent at a Hospital with On-Site Interpreter Services. J Gen Intern Med. 2007;22(S2):294299.

24. Lee KC, Winickoff JP, Kim MK, et al. Resident physicians' use of professional and nonprofessional interpreters: a national survey. JAMA. 2006;296(9):1050-3.

25. Karliner LS, Perez-Stable EJ, Gildengorin G. The language divide. The importance of training in the use of interpreters for outpatient practice. $J$ Gen Intern Med. 2004;19(2):175-83.

26. Patton MQ. Qualitative Research and Evaluation Methods. Thousand Oaks, CA: Sage Publications; 2002.

27. Kroon C. Written Communication - Coordinator, Interpreter Education and Quality Improvement, Yale-New Haven Hospital. June 2007 and October 2008.

28. Garcia-Orme G, Dao, DM. Written Communication, Director of Interpreter Services, Interpreter Services Department Supervisor, San Francisco General Hospital. March 2006 and October, 2008.

29. Fernandez A, Schillinger D, Grumbach $\mathbf{K}$, et al. Physician language ability and cultural competence. An exploratory study of communication with Spanish-speaking patients. J Gen Intern Med. 2004;19(2):167-74.

30. Morse JM. The Significance of Saturation. Qual Health Res. 1995;5 (2): 147-9.

31. Glaser BG, Strauss AL. The Discovery of Grounded Theory: Strategies for Qualitative Research. Chicago: Aldine Publishing Company; 1967.

32. Crabtree BF Miller WL, eds. Doing Qualitative Research (Research Methods for Primary Care). Thousand Oaks, CA: Sage Publications; 1999: 33-46.

33. Bradley EH, Curry LA, Devers KJ. Qualitative data analysis for health services research: developing taxonomy, themes, and theory. Health Serv Res. 2007;42(4): 1758-72.

34. Miles MB, Huberman M. Qualitative Data Analysis, 2nd edition. Thousand Oaks, CA: Sage Publications; 1994.

35. Pope C, Mays N. Reaching the parts other methods cannot reach: an introduction to qualitative methods in health and health services research. BMJ. 1995;311(6996):42-5.

36. Saba GW, Wong ST, Schillinger D, et al. Shared decision making and the experience of partnership in primary care. Annals of Family Medicine. 2006;4(1):54-62.

37. Rivadeneyra R, Elderkin-Thompson V, Silver RC, Waitzkin H. Patient centeredness in medical encounters requiring an interpreter. Am J Med. 2000; 108(6):470-4

38. Ferguson WJ. Un Poquito: The benefits and perils of knowing "a little bit" of Spanish when communicating with Spanish-speaking patients. Health Aff. 2008;27(6):1695-700.

39. Schenker Y, Lo B, Ettinger KM, Fernandez A. Navigating Language Barriers under Difficult Circumstances. Ann Intern Med. 2008;149 (4):264-9. August 19.

40. Regenstein M. Measuring and Improving the Quality of Hospital Language Services: Insights from the Speaking Together Collaborative. J Gen Intern Med. 2007;22(S2):356-9.

41. Klein KJ, Sorra JS. The Challenge of Innovation Implementation. Acad Manage Rev. 1996;21(4):1055-80.

42. Schyve PM. Language Differences as a Barrier to Quality and Safety in Health Care: The Joint Commission Perspective. J Gen Intern Med. 2007;22(S2):360-1.

\section{APPENDIX: STANDARD INTERVIEW GUIDE WITH PROBES}

1. Thinking back to your last rotation at [HOSPITAL], please tell me about a time when you used an interpreter (either someone informally or someone from interpreter services)? (If person says they never use interpreters, skip to \#3)

a. Tell me about your decision to call an interpreter. Probes:

- What clinical task were you trying to accomplish/why call? (e.g. inability to communicate, 
informed consent, end of life care, treatment planning, discharge instructions, etc.)

- What's your routine practice when caring for patients who don't speak English well? How often do you use interpreters?

- Does your resident/attending care/know about your practices?

- Do you ever regret calling/not calling?

b. Tell me about how it worked.

Probes:

- Did you call interpreter services or did you get someone else who was around to help you interpret?

Probes if interpreter services was called:

- Who called?

- Who came to help?

- Perceived utility/accuracy of interaction?

- How did the interaction go?

- Were there any surprises?

Probes if non-professional interpreter called:

- Who helped you interpret? (Nurse, medical assistant, housekeeping, family member?)

- Tell me how that went.

- How did you find the person to help?

- Perceived utility/accuracy of interaction?

- Were there any surprises?
2. Tell me about a time when you didn't use an interpreter for a patient who wasn't fluent in English? What was that like?

Probes:

- What clinical task were you trying to accomplish (informed consent, end of life discussion, discharge planning, etc)?

- Do you think that not using an interpreter affected the task?

- What made you decide not to use an interpreter?

- Did you let anyone know you did not use an interpreter?

3. Can you think of a time that communication trouble with non-English speaking patients has lead to errors or nearmisses? Tell me more about that.

4. What would make it easier for you to use interpreters?

Probe:

- Systems changes, increased staff awareness/ education, training in the use of interpreters, awareness of their availability and how to get them quicker, other supports?

5. If you could make one recommendation to the hospital about how to better communicate with and care for patients with limited English proficiency, what would it be?

6. Is there anything else you think we should know about residents' use of interpreters? 